\title{
Comparison of emotional intelligence levels of soccer players according to age and playing position
}

\author{
Yusuf Soylu ${ }^{\otimes}$ \\ Faculty of Sport Sciences, Tokat Gaziosmanpasa University, Tokat, Turkey
}

\begin{abstract}
Background: Several studies have compared the physical, physiological and anthropometric characteristics according to age and playing position in soccer. However, no studies have researched the comparison of emotional intelligence (EI) levels of soccer players. Objective: The purpose of this study was to compare the El levels of soccer players in their age and playing position. Methods: A total of 550 male soccer players were divided into four groups according to their age: under-17 $(n=135)$, under-19 $(n=131)$, under-21 $(n=144)$ and $22+(n=140)$ and playing position: goalkeeper $(n=101)$, defender $(n=159)$, midfielder $(n=148)$ and forward $(n=142)$. El levels of soccer were evaluated through the Emotional Intelligence Inventory in Sport. Results: Players in the lowest age category showed significantly $(p<.001)$ higher El level. Moreover, midfielders have also significantly $(p=.039)$ higher El level than other players. Conclusions: The results of this study indicated that the level of El varies according to players' age and playing position. These findings might be used for the evaluation of psychological and physiological responses required for soccerspecific performance.
\end{abstract}

Keywords: emotional intelligence, soccer, playing position, psychological responses

\section{Introduction}

Soccer is a sport characterized by a high-intensity intermittent load, requiring jumping, shooting, tackling, turnings, sprinting, controlling the ball under pressure, running at different speeds, and sliding tackles with an average game intensity ranging from $80 \%$ to $90 \%$ of players' individual maximum heart rate (Hill-Haas et al., 2011; Stølen et al., 2005). Previous studies have shown that soccer players cover a distance between $6.1 \mathrm{~km}$ and $10.3 \mathrm{~km}$ during competitive matches (Castagna et al., 2009). The results of some studies show that successful and effective match performance responses were affected by not only physiological responses but also by technical and tactical match characteristics during soccer matches. Furthermore, these affecting factors depend on the interaction of psychological responses (Gil et al., 2007).

One of the important factors affecting sports performance are emotions such as happiness, anxiety and anger (Jones, 2003). For team or individual athletes in order to perform successful performance under the competitive pressure induced a wide range of emotional responses which have the potential to influence performance (Laborde et al., 2013, 2016; Nieuwenhuys et al., 2008). Numerous studies have confirmed that emotional intelligence (EI) has been related to many factors associated with sports performance such as emotion regulation (Kotsou et al., 2011; Laborde et al., 2011), psychological states (Lane
\& Wilson, 2011) and coping strategies (Cowden, 2016). It is well known from previous study results that there is a relationship between playing position and using psychological skills in soccer (Thelwell et al., 2007). In modern soccer, midfielders (playmakers) act as a bridge between defence and attack for the transition of the game (Clemente et al., 2015; Korte \& Lames, 2018; López-Peña \& Touchette, 2012). Thus, increased positive team interactions between playing positions may affect tactical organization both defensive and attacking, team networking and soccer-specific performance during a modern soccer match (Clemente et al., 2015; Slimani et al., 2016; Thelwell et al., 2007). Therefore, competitor athletes should train their emotions in order to consistently cope with the stress and to increase attention and decision-making ability level during competitions and matches.

Similarly to other team sports such as basketball, handball and volleyball, numerous studies investigated physiological responses (Lago-Peñas et al., 2011), physical (Kammoun et al., 2020) and technical characteristics (Dellal et al., 2010) of soccer players in different leagues, ages and performance levels according to playing position. However, no study attempted to examine the EI levels of young soccer players according to their age and playing position. Thus, the purpose of this study was to compare the EI levels of soccer players in their age and playing position. Previous studies confirmed that adolescents are more

$\square$ Corresponding author: Yusuf Soylu, e-mail soylusyusuf@gmail.com, ORCID ${ }^{\circledR}$ record https://orcid.org/0000-0003-0609-0601

Article history: Received August 21 2020, Accepted March 18 2021, Published April 302021

Copyright: @ 2021 The Author(s). Published by Palacký University Olomouc. This is an open access article distributed under the terms of the Creative Commons Attribution License (https://creativecommons.org/licenses/by/4.0/), which permits unrestricted use, distribution, and reproduction in any medium, provided the original author and source are credited. This license does not cover any third-party material that may appear with permission in the article. 
active, open-minded and also adaptive to problem-solving (Alumran \& Punamäki, 2008; Seiffge-Krenke \& Klessinger, 2000). Therefore, we hypothesized that the youngest players and midfielders have higher EI level than the other age category and playing position.

\section{Methods}

\section{Participants}

The participants were regional amateur Turkish male soccer players accustomed to a training workload of more than 4 training units per week and involved in soccer training and matches for at least 5 years in their current playing position. They were fully informed about the study before filling out the questionnaires and signed an informed consent; in nonadults, informed consent was signed by legal representatives. Data collection took place in each club's training centre via paper-and-pencil in pre-season 2020-2021. The questionnaire took approximately 20-25 minutes to complete.

At the beginning of the study, 607 male soccer players were divided into four groups according to age category: under-17 (U-17; $n=159)$, under-19 (U-19; $n=140)$, under-21 (U-21; $n=157)$ and 22 plus $(22+; n=151)$ and playing position: goalkeeper $(n=108)$, defender $(n=177)$, midfielder $(n=168)$ and forward $(n=154)$. Subsequently, a total of 57 players ( 24 from the U-17, 9 from the U-19, 13 from the U-21 and 11 from the 22+ [range from 22 to 26]) were excluded because of various reasons (e.g., unwillingness to complete the scale and uncompleted scale), resulting in a dropout rate of approximately $10 \%$. The final study sample included 550 players divided into four groups according to their age: under-17 $(n=135)$, under$19(n=131)$, under $-21(n=144)$ and $22+(n=140)$ and playing position: goalkeeper $(n=101)$, defender $(n=159$, midfielder $(n=148)$ and forward $(n=142)$.

The study was approved by the Osmaniye Korkut Ata University Ethics Committee (2020/37/2) and was conducted in a manner consistent with the institutional ethical requirements for human experimentation in accordance with the Declaration of Helsinki.

\section{Instruments and procedure}

The data collection was conducted over a month for all team beginning with the survey consisting of general socio-demographic questions. The Emotional Intelligence Scale (EIS) was developed by Schutte et al. (1998) and based on the ability model in a study by Mayer et al. (2008). The scale contains 33 items. Solanki and Lane (2010) reported that sport and exercise context generally requires self-report measures to be brief. The Emotional Intelligence Scale for use in sport was developed by Lane, Meyer, et al. (2009). The scale has 19 items $(\alpha=.73)$. Turkish version of Emotional Intelligence Inventory in Sport (EIIS) for use among athletic sample which has 18 items $(\alpha=.91)$ on a 5 -point Likert scale anchored from $1=$ strongly disagree to $5=$ strongly agree, with scores polarized ranging from 18 (low) to 90 (high) and has been validated as a marker of emotions in Turkish sample (Adiloğulları \& Görgülü, 2015). The five factors of the
EIIS are appraisal of others' emotions $(\alpha=.69)$, appraisal of own emotions $(\alpha=.85)$, emotion regulation $(\alpha=.67)$, social skills $(\alpha=.61)$, utilization of emotions $(\alpha=.85)$. The scale included four items of appraisal of others' emotions, three items of appraisal of own emotions, two items of emotion regulation, and three items of social skills and six items of the utilization of emotions. In the present study, the alpha coefficient for the five factors scales in the current study was appraisal of others' emotions $(\alpha=.67)$, appraisal of own emotions $(\alpha=.71)$, emotion regulation $(\alpha=.67)$, social skills $(\alpha=.61)$, utilization of emotions $(\alpha=.73)$ and EIIS $(\alpha=.92)$.

\section{Statistical analyses}

Data were reported as means and standard deviations. An exploratory analysis of data was conducted. Normality assumptions were confirmed using the KolmogorovSmirnov test. A one-way analysis of variance test was used in order to compare the differences between players' age category and playing positions. When there were differences in the analysis of variance test, the Tukey post-hoc test was used. To estimate the strength of significant findings, effect size partial eta-squared was used. Effect size values were interpreted as follows: $\geq .01$ corresponds to a small effect, $\geq .06$ represents a medium effect and $\geq .14$ is considered as a large effect. All statistical analyses were performed using IBM SPSS Statistics (Version 22; IBM, Armonk, NY, USA), and the level of statistical significance was established at $\alpha=.05$.

\section{Results}

The soccer players average scores of EIIS $(M \pm S D)$ were $3.66 \pm 0.63$, their average score for appraisal of others' emotions $3.77 \pm 0.74$, their appraisal of own emotions $3.89 \pm 0.86$, their emotion regulation $3.48 \pm 1.04$, their social skills $3.30 \pm 0.99$, and their utilization of emotions $3.72 \pm 0.72$.

Table 1 shows the level of EI of soccer players according to their age category. The table also demonstrates that players in the lowest age category showed significantly $(p<.001)$ higher EI level than the others except for appraisal of their own emotions.

The level of EI and appraisal of other emotions of midfielders were significantly ( $p \leq 0.05$ ) higher compared with the other playing positions such as goalkeeper, defender and forward (Table 2).

\section{Discussion}

To our knowledge, the present study is the first to examine the EI levels in male soccer players according to age and playing position. Many previous studies had investigated EI in individual and team sports. With the exception of a recent study that assessed female soccer players (Rutkowska $\&$ Bergier, 2015), the majority of studies have investigated other team sports such as rugby, basketball and cricket (Cowden, 2016; Lane et al., 2010; Zizzi et al., 2003). Because of the soccer-specific physical, physiological and 
Table 1 The level of emotional intelligence of soccer players according to their age category

\begin{tabular}{lcccc}
\hline Emotional intelligence sub-scale & $F(3,546)$ & $p$ & $\eta_{p}^{2}$ & Tukey post-hoc \\
\hline Appraisal of others' emotions & 11.155 & .001 & .058 & $\mathrm{U}-17>\mathrm{U}-19, \mathrm{U}-21$ and 22+ \\
Appraisal of own emotions & 6.997 & .001 & .037 & $\mathrm{U}-21>\mathrm{U}-17, \mathrm{U}-19$ and 22+ \\
Emotion regulation & 7.994 & .001 & .042 & $\mathrm{U}-17>\mathrm{U}-19, \mathrm{U}-21$ and 22+ \\
Social skills & 22.037 & .001 & .108 & $\mathrm{U}-17>\mathrm{U}-19, \mathrm{U}-21$ and 22+ \\
Utilization of emotions & 8.393 & .001 & .044 & $\mathrm{U}-17>\mathrm{U}-19, \mathrm{U}-21$ and 22+ \\
Emotional intelligence & 16.918 & .001 & .085 & $\mathrm{U}-17>\mathrm{U}-19, \mathrm{U}-21$ and 22+ \\
\hline
\end{tabular}

Table 2 The level of emotional intelligence of soccer players according to their playing position

\begin{tabular}{|c|c|c|c|c|}
\hline Emotional intelligence sub-scale & $F(3,546)$ & $p$ & $\eta_{p}^{2}$ & Tukey post-hoc \\
\hline Appraisal of others' emotions & 3.639 & .013 & .020 & Mid $>$ Gk, Def and For \\
\hline Appraisal of own emotions & 1.418 & .237 & .010 & \\
\hline Emotion regulation & 1.557 & .199 & .011 & \\
\hline Social skills & 1.117 & .342 & .000 & \\
\hline Utilization of emotions & 1.530 & .206 & .011 & \\
\hline Emotional intelligence & 2.727 & .043 & .015 & Mid $>$ Gk, Def and For \\
\hline
\end{tabular}

Note. $\mathrm{Gk}=$ goalkeeper; Def = defender; Mid = midfielder; For = forward.

psychological demands, their findings are not generalized with the soccer players.

Successful performance in a team sport is a various combination of variables such as physical, physiological and psychological responses. Furthermore, in soccer, it is well known that evaluating the soccer-specific requirements of soccer players according to different playing levels, playing position and age categories might provide detailed information in order to prepare them for higher playing levels in their career (Nikolaidis et al., 2014; Stølen et al., 2005). In accordance with many previous studies in soccer literature, our players were divided into four main groups according to their playing positions (Gil et al., 2007; Hazir, 2010; Wong et al., 2009). One of the important findings of this study showed that the level of EI of midfielders was significantly higher compared with the other playing positions such as goalkeeper, defender and forwards. It is not easy to discuss our results with existing research due to the lack of research findings on this topic in the field of applied sports psychology. However, results from other fields of psychology and physiology may provide some evidence that could help to interpret our findings regarding EI, age and playing position in soccer.

Soccer players require well developed physical characteristics and also technical skills in order to perform highintensity actions both with and without the ball. Therefore, it is widely accepted that the physical performance and technical activities of soccer players are closely related to their playing position in the team. In modern soccer, midfield players were shorter and lighter compared to the other positions and this is considered to provide an advantage for them to move more efficiently and cover longer distances on the pitch (Hazir, 2010). In addition, midfielders performed more high-intensity running than other playing position groups (Di Salvo et al., 2009). These characteristics allow them to be effective playmaker role, to deliver the ball to both sides of the pitch. In accordance with the results from our study, a significant difference was found between the midfielder and the other group's characteristics in terms of the appraisal of others' emotions and EI. It is important that the high technical skills and decision-making ability of midfielders might be determined and affected by the score of the match. Decision making has complex cognitive skills and the quality of decision making is a key determinant of successful sports performance (Raab \& Johnson, 2004; Taatgen, 2013). Furthermore, many studies have shown that emotions play important role in risk-related decisionmaking under pressure (Laborde et al., 2013; Panno et al., 2015). Therefore, team coaches should train especially midfielders who help both defender and forward to consistently coping with the stress, to increase attention and decisionmaking ability during both physical and mental training.

While some studies investigated the EI and age relationship in sedentary individuals (Bar-On \& Parker, 2000; Goleman, 1996), another study examined the performance associated with the EI in athletes (Laborde et al., 2014). Therefore, there are many contradictory study results in the literature regarding the relationship between age and EI levels. Contrast to some studies (Dumčienè et al., 2020; Fariselli et al., 2008), another striking result from this study is that playing soccer in the lowest age-induced higher EI level compared with the other higher age levels similar with a few studies (Alumran \& Punamäki, 2008). Except for physical performance and technical activities, the players' emotional intelligence might be an affecting and important factor in determining the quality of the game. In literature, numerous studies have associated with a higher level of EI and sports performance and high EI might provide an advantage for athletes in order to perform better performance (Crombie, Lombard, \& Noakes, 2009; Laborde et al., 2011; Lane et al., 2010; Tok et al., 2013) and to use more effective coping strategies during competition (Laborde et al., 2014) and to use psychological skills (Lane Meyer, et al., 2009; Lane, Thelwell, et al., 2009). The 
possible explanations for such different outcomes in literature might be explained by the different sports branches, sexes and age groups. In addition, from a practical point of view, a different type of measurement instruments based on different EI theory might be affecting the EI results in the literature. For example, previous studies supported that the younger athletes are more active, open-minded and also adaptive to problem-solving (Alumran \& Punamäki, 2008; Seiffge-Krenke \& Klessinger, 2000). Furthermore, the effects of EI on team sports such as cricket, basketball and hockey and individual sports like tennis and ballet dance are found very vary in the systematic review of EI in sport and physical activity (Laborde et al., 2016). Taking these results into consideration, we need more scientific researches to explore the connection between EI and sports performance in terms of age, sexes and sports branches.

There are several limitations of our study that should be taken into consideration before final conclusions are drawn. Firstly, we did not measure the athletics expertise and relative age of players. These might be affecting factors for the EI levels of players. Secondly, the EI may be affected by not only training experience, but also by current playing position. Therefore, future studies should be taken into consideration our study results. In addition, for further investigations, it would be interesting to divide into six groups for players according to playing positions. Therefore, our results might not be generalized for different age and sex group players. A major strength of this study is the large sample size.

\section{Conclusions}

The present study gives an important contribution to the existing literature about EI, age and playing position of soccer players. The present study demonstrated that the level of EI in soccer players is affected by their age and playing positions. It is suggested that further research is required to investigate the combination of performance responses and EI. The EI training should be used in order to evaluate psychological responses related to physical and physiological demands in soccer players.

\section{Conflict of interest}

The authors report no conflict of interest.

\section{References}

Adiloğulları, İ., \& Görgülü, R. (2015). Sporda Duygusal Zekâ Envanteri'nin Uyarlama Çalışması [The adaption study of Emotional Intelligence Inventory in Sport]. International Journal of Sport, Exercise \& Training Sciences, 1(2), 83-94. https://doi.org/10.18826/ijsets.05333

Alumran, J. I. A., \& Punamäki, R.-L. (2008). Relationship between gender, age, academic achievement, emotional intelligence, and coping styles in Bahraini adolescents. Individual Differences Research, 6(2), 104-119.

Bar-On, R., \& Parker, J. D. A. (Eds.). (2000). Handbook of emotional intelligence: The theory and practice of development, evaluation, education, and implementation-at home, school, and in the workplace. Jossey-Bass.

Castagna, C., Impellizzeri, F., Cecchini, E., Rampinini, E., \& Alvarez, J. C. B. (2009). Effects of intermittent-endurance fitness on match performance in young male soccer players. Journal of Strength and Conditioning Research, 23(7), 19541959. https://doi.org/10.1519/JSC.0b013e3181b7f743

Clemente, F. M. Martins, F. M. L. Wong, P. D. Kalamaras, D. \& Mendes, R. S. (2015). Midfielder as the prominent participant in the building attack: A network analysis of national teams in FIFA World Cup 2014. International Journal of Performance Analysis in Sport, 15(2), 704-722. https://doi.org/10.1080/24 748668.2015 .11868825

Cowden, R. G. (2016). Mental toughness, emotional intelligence, and coping effectiveness: An analysis of construct interrelatedness among high-performing adolescent male athletes. Perceptual and Motor Skills, 123(3), 737-753. https://doi.org/10.1177/0031512516666027

Crombie, D., Lombard, C., \& Noakes, T. (2009). Emotional intelligence scores predict team sports performance in a national cricket competition. International Journal of Sports Science \& Coaching, 4(2), 209-224. https://doi org/10.1260/174795409788549544

Dellal, A., Wong, D. P., Moalla, W., \& Chamari, K. (2010). Physical and technical activity of soccer players in the French First League - with special reference to their playing position. International SportMed Journal, 11(2), 278-290. https:// hdl.handle.net/10520/EJC48393

Di Salvo, V., Gregson, W., Atkinson, G., Tordoff, P., \& Drust, B. (2009). Analysis of high intensity activity in Premier League soccer. International Journal of Sports Medicine, 30(3), 205-212. https://doi.org/10.1055/s-0028-1105950

Dumčienė, A., Bilevičienè, S., \& Sipavičiūtè, B. (2020). Expression of emotional intelligence among tennis players. Baltic Journal of Sport and Health Sciences, 2(117), 21-27. https://doi.org/10.33607/bjshs.v2i117.914

Fariselli, L., Ghini, M., \& Freedman, J. (2008). Age and emotional intelligence. Six Seconds: The Emotional Intelligence Network. https://prodimages.6seconds.org/ media/WP EQ and Age.pdf

Gil, S. M., Gil, J., Ruiz, F., Irazusta, A., \& Irazusta, J. (2007). Physiological and anthropometric characteristics of young soccer players according to their playing position: Relevance for the selection process. Journal of Strength and Conditioning Research, 21(2), 438-445. https://doi.org/10.1519/R-19995.1

Goleman, D. (1996). Emotional intelligence: Why it can matter more than IQ. Bloomsbury Publishing.

Hazir, T. (2010). Physical characteristics and somatotype of soccer players according to playing level and position. Journal of Human Kinetics, 26, 83-95. http:// www.johk.pl/files/011 hazir.pdf

Hill-Haas, S. V., Dawson, B., Impellizzeri, F. M., \& Coutts, A. J. (2011). Physiology of small-sided games training in football. Sports Medicine, 41(3), 199-220. https://doi.org/10.2165/11539740-000000000-00000

Jones, M. V. (2003). Controlling emotions in sport. Sport Psychologist, 17(4), 471-486. https://doi.org/10.1123/tsp.17.4.471

Kammoun, M. M., Trabelsi, O., Gharbi, A., Masmoudi, L., Ghorbel, S., Tabka, Z., \& Chamari, K. (2020). Anthropometric and physical fitness profiles of Tunisian female soccer players: Associations with field position. Acta Gymnica, 50(3), 130-137. https://doi.org/10.5507/ag.2020.013

Korte, F., \& Lames, M. (2018). Characterizing different team sports using network analysis. Current Issues in Sport Science (CISS), 3(5), 1-11. https://doi. org/10.15203/CISS 2018.005

Kotsou, I., Nelis, D., Grégoire, J., \& Mikolajczak, M. (2011). Emotional plasticity: Conditions and effects of improving emotional competence in adulthood. Journal of Applied Psychology, 96(4), 827-839. https://doi.org/10.1037/a0023047

Laborde, S., Brüll, A., Weber, J., \& Anders, L. S. (2011). Trait emotional intelligence in sports: A protective role against stress through heart rate variability? Personality and Individual Differences, 51(1), 23-27. https://doi.org/10.1016/j. paid.2011.03.003

Laborde, S., Dosseville, F., \& Allen, M. S. (2016). Emotional intelligence in sport and exercise: A systematic review. Scandinavian Journal of Medicine \& Science in Sports, 26(8), 862-874. https://doi.org/10.1111/sms.12510

Laborde, S., Dosseville, F., Guillén, F., \& Chávez, E. (2014). Validity of the trait emotional intelligence questionnaire in sports and its links with performance satisfaction. Psychology of Sport and Exercise, 15(5), 481-490. https://doi. org/10.1016/i.psychsport.2014.05.001

Laborde, S., Dosseville, F., \& Raab, M. (2013). Introduction, comprehensive approach, and vision for the future. International Journal of Sport and Exercise Psychology, 11(2), 143-150. https://doi.org/10.1080/1612197X.2013.773686

Lago-Peñas, C., Casais, L., Dellal, A., Rey, E., \& Domínguez, E. (2011). Anthropometric and physiological characteristics of young soccer players according to their playing positions: Relevance for competition success. Journal of Strength and Conditioning Research, 25(12), 3358-3367. https://doi.org/10.1519/ JSC.0b013e318216305d

Lane, A. M., Devonport, T. J., Soos, I., Karsai, I., Leibinger, E., \& Hamar, P. (2010). Emotional intelligence and emotions associated with optimal and dysfunctional athletic performance. Journal of Sports Science and Medicine, 9(3), 388-392. https://doi.org/10.7790/ejap.v5i1.123

Lane, A. M., Meyer, B. B., Devonport, T. J., Davies, K. A., Thelwell, R., Gill, G. S., Diehl, C. D. P., Wilson, M., \& Weston, N. (2009). Validity of the emotional intelligence scale for use in sport. Journal of Sports Science and Medicine, 8(2), 289-295. https://doi.org/10.1080/10413200601102904

Lane, A. M., Thelwell, R. C., Lowther, J., \& Devonport, T. J. (2009). Emotional intelligence and psychological skills use among athletes. Social Behavior and Personality: An International Journal, 37(2), 195-201. https://doi.org/10.2224/ sbp.2009.37.2.195

Lane, A. M., \& Wilson, M. (2011). Emotions and trait emotional intelligence among ultra-endurance runners. Journal of Science and Medicine in Sport, 14(4), 358-362. https://doi.org/10.1016/j.jsams.2011.03.001 
López-Peña, J., \& Touchette, H. (2012). A network theory analysis of footbal strategies. In C. Clanet (Ed.), Sports Physics: Proceedings of 2012 Euromech Physics of Sports Conference (pp. 517-528). Éditions de l'École Polytechnique.

Mayer, J. D., Salovey, P., \& Caruso, D. R. (2008). Emotional intelligence: New ability or eclectic traits? American Psychologist, 63(6), 503-517. https://doi. org/10.1037/0003-066X.63.6.503

Nieuwenhuys, A., Pijpers, J. R., Oudejans, R. R. D., \& Bakker, F. C. (2008). The influence of anxiety on visual attention in climbing. Journal of Sport and Exercise Psychology, 30(2), 171-185. https://doi.org/10.1123/isep.30.2.171

Nikolaidis, P., Ziv, G., Lidor, R., \& Arnon, M. (2014). Inter-individual variability in soccer players of different age groups playing different positions. Journal of Human Kinetics, 4O(1), 213-225. https://doi.org/10.2478/hukin-2014-0023

Panno, A., Anna Donati, M., Chiesi, F., \& Primi, C. (2015). Trait emotional intelligence is related to risk-taking through negative mood and anticipated fear. Social Psychology, 46(6), 361-367. https://doi.org/10.1027/1864-9335/a000247

Raab, M., \& Johnson, J. G. (2004). Individual differences of action orientation for risk taking in sports. Research Quarterly for Exercise and Sport, 75(3), 326-336. https://doi.org/10.1080/02701367.2004.10609164

Rutkowska, K., \& Bergier, J. (2015). Psychological gender and emotional intelligence in youth female soccer players. Journal of Human Kinetics, 47, 285-291. https://doi.org/10.1515/hukin-2015-0084

Schutte, N. S., Malouff, J. M., Hall, L. E., Haggerty, D. J., Cooper, J. T., Golden, C. J., \& Dornheim, L. (1998). Development and validation of a measure of emotional intelligence. Personality and Individual Differences, 25(2), 167-177. https://doi. org/10.1016/S0191-8869(98)00001-4

Seiffge-Krenke, I., \& Klessinger, N. (2000). Long-term effects of avoidant cop ing on adolescents' depressive symptoms. Journal of Youth and Adolescence, 29(6), 617-630. https://doi.org/10.1023/A:1026440304695
Slimani, M., Bragazzi, N. L., Tod, D., Dellal, A., Hue, O., Cheour, F., Taylor, L., \& Chamari, K. (2016). Do cognitive training strategies improve motor and positive psychological skills development in soccer players? Insights from a systematic review. Journal of Sports Sciences, 34(24), 2338-2349. https://doi.org/10.1080/0 2640414.2016.1254809

Solanki, D., \& Lane, A. M. (2010). Relationships between exercise as a mood regulation strategy and trait emotional intelligence. Asian Journal of Sports Medicine, 1(4), 195-200. https://doi.org/10.5812/asjsm.34831

Stølen, T., Chamari, K., Castagna, C., \&Wisløff,U. (2005). Physiologyof soccer. Sports Medicine, 35(6), 501-536. https://doi.org/10.2165/00007256-200535060-00004

Taatgen, N. A. (2013). The nature and transfer of cognitive skills. Psychological Review, 120(3), 439-471. https://doi.org/10.1037/a0033138

Thelwell, R. C., Greenlees, I. A., \& Weston, N. J. V. (2007). Using psychological skills training to develop soccer performance. Journal of Applied Sport Psychology, 18(3), 254-270. https://doi.org/10.1080/10413200600830323

Tok, S., Binboğa, E., Guven, S., Çatıkkas, F., \& Dane, S. (2013). Trait emotional intelligence, the Big Five personality traits and isometric maximal voluntary contraction level under stress in athletes. Neurology, Psychiatry and Brain Research, 19(3), 133-138. https://doi.org/10.1016/j.npbr.2013.04.005

Wong, P.-L., Chamari, K., Dellal, A., \& Wisløff, U. (2009). Relationship between anthropometric and physiological characteristics in youth soccer players. Journal of Strength and Conditioning Research, 23(4), 1204-1210. https://doi. org/10.1519/JSC.0b013e31819f1e52

Zizzi, S., Deaner, H., \& Hirschhorn, D. (2003). The relationship between emotional intelligence and performance among college basketball players. Journal of Applied Sport Psychology, 15(3), 262-269. https://doi.org/10.1080/10413200305390 